\title{
A LITERATURA COMO DIREITO FUNDAMENTAL E A VIABILIZAÇÃO DESTE DIREITO PELO MÉTODO RECEPCIONAL E OUTRAS METODOLOGIAS
}

\author{
LITERATURE AS FUNDAMENTAL RIGHT AND THE REALIZATION OF THIS RIGHT \\ BY RECEPCIONAL METHOD AND OTHER METHODS
}

\author{
Lóide Lacerda (UTFPR-Curitiba) ${ }^{1}$ \\ Alice Atsuko Matsuda (UTFPR-Curitiba) ${ }^{2}$
}

\begin{abstract}
RESUMO: A Constituição Federal do Brasil prevê amplo acesso à educação como direito fundamental da criança e do adolescente e há mecanismos legais que combatem e punem a falta de efetividade desse direito. Entretanto, sabe-se que há vários problemas educacionais no sistema educacional público brasileiro, principalmente, quanto ao desenvolvimento de habilidades de leitura e escrita dos alunos e, como resposta a essa problemática, pesquisadores têm desenvolvido métodos efetivos para melhorar o desempenho linguístico e literário dos alunos. Este artigo objetiva descrever os estudos teóricos realizados no Plano de Trabalho em Iniciação Científica intitulado "A Literatura como Direito Fundamental e a viabilização desse direito pelo Método Recepcional", vinculado ao Projeto de pesquisa homologado no edital 04/2013 - PR 0058, "Literatura infanto-juvenil e a formação do leitor: a representação discursiva do trabalho e da tecnologia", do grupo de pesquisa "Discursos sobre Tecnologia, Trabalho e Identidades Nacionais", do Programa de Pós-graduação em Tecnologia da Universidade Tecnológica Federal do Paraná - UTFPR (Campus Curitiba). A pesquisa busca fazer um levantamento bibliográfico dos Direitos Fundamentais, da Teoria da Estética da Recepção e de propostas metodológicas de ensino de Literatura. A pesquisa também se propõe a analisar obras sociológicas acerca da educação e da cultura na sociedade contemporânea, a fim de estabelecer relações entre o acesso à literatura como direito fundamental e as demandas da atualidade. $\mathrm{O}$ artigo busca desenvolver também uma sequência didática para auxílio da prática pedagógica a partir de obras da literatura infantil e juvenil, focalizando a representação da tecnologia, do trabalho e da construção de identidades.
\end{abstract}

PALAVRAS-CHAVE: Constituição Federal. Dignidade da Pessoa Humana. Função da Literatura. Método Recepcional.

ABSTRACT: The Federal Constitution of Brazil provides full access to education as a fundamental right to children and adolescents and there are legal mechanisms that combat and punish the lack of effectiveness of it. However, it is known that there are several educational problems in the Brazilian educational public system, mainly in teaching strategies to develop students reading and writing abilities and as a response to this problem, researchers have developed methods for effective teaching literature to improve the linguistic and literary students' performance. This article aims to describe the theoretical

\footnotetext{
1 Acadêmica do curso de Licenciatura em Letras Português e Inglês da Universidade Tecnológica Federal do Paraná. Artigo desenvolvido durante a vigência do Programa Institucional de Bolsas de Iniciação Científica (UTFPR-CT). Pós-Graduação lato sensu em Neuropedagogia na Educação, pela Instituição: Fatec (Faculdade de Tecnologia do Vale do Ivaí). Bacharel em Direito, na Faculdade Dom Bosco. E-mail: lacerdaloide@gmail.com

2 Professora Dra. Alice Atsuko Matsuda, Doutor em Letras pela Universidade Estadual de Londrina (UEL), professor titular - Adjunto 3 - da Universidade Tecnológica Federal do Paraná-Campus Curitiba, do Departamento Acadêmico de Linguagem e Comunicação - DALIC. Docente Permanente do Programa de Pós-Graduação em Estudos de Linguagens (PPGEL). Participa como membro dos Grupos de Pesquisas Discursos sobre Trabalho, Tecnologia e Identidades; Grupo de Pesquisa em Linguística Aplicada (GRUPLA) e como vice-líder do Grupo de Pesquisa (Des)caminhos da modernidade ao contemporâneo: estudos em literatura e outras linguagens. CuritibaPR, Brasil. E-mail: alicem@utfpr.edu.br
} 
studies in the Work Plan for Scientific Initiation titled Literature as a Fundamental Right and the feasibility of this right by Recepcional Method. It is linked to the approved research project in the announcement 04/2013 - PR 0058, Children's literature and the formation of the reader: the discursive representation of labor and technology. Such project is from the research group Discourses on technology, Labor and National Identity, of the Graduate Program in Technology of Federal Technological University of Paraná - UTFPR (Campus Curitiba). This research seeks to review the literature of Fundamental Rights, Theory of Aesthetic Reception and methodological proposals for teaching Literature. The research also aims at analyzing sociological studies about education and culture in contemporary society in order to establish some relationships between the access to literature as a fundamental right and the demands today. The article develops a teaching sequence to support the teaching practice from the works of child and adolescent literature. This teaching sequence focus on the representation of technology, work and the construction of identities in order to help teachers to improve their practice.

KEYWORDS: Federal Constitution. Human Dignity. Function of Literature. Recepcional Method.

\section{Introdução}

A Constituição Federal de 1988 estabeleceu a igualdade de direitos a todos, sem distinção de qualquer natureza, proibindo a sua violabilidade. O mesmo diploma jurídico garantiu, com absoluta prioridade à criança e ao adolescente, o direito à educação como dever do Estado e da família, cabendo à sociedade promovê-la e incentivá-la.

As Diretrizes Curriculares do Ensino de Língua Portuguesa do Paraná sugerem a aplicação dos pressupostos teóricos da Estética da Recepção para o ensino de literatura na escola, visando formar um leitor apto a sentir e expressar o que sentiu nas aulas de literatura, reconhecendo um envolvimento de subjetividades expressos pela tríade obra/autor/leitor por meio da interação presente na prática de leitura.

Considerando o disposto na Constituição Federal de 1988, documento em vigência que institui o Estado Democrático de Direitos e assegura o exercício dos direitos, e o disposto nas Diretrizes Curriculares do Ensino de Língua Portuguesa do Paraná, o presente artigo busca fazer um levantamento bibliográfico dos Direitos Fundamentais, da Teoria da Estética da Recepção e de propostas metodológicas de ensino de Literatura. Com base em tais dados bibliográficos, será desenvolvido um modelo de sequência didática a partir de obras da literatura infantil e juvenil, focalizando a representação da tecnologia, do trabalho e da construção de identidades. Para tanto, serão explanados conceitos jurídicos como "dignidade da pessoa humana" e "direito fundamental" e serão feitas análises de obras sociológicas, buscando investigar temas relevantes à educação nas sociedades contemporâneas, a fim de estabelecer relações entre o acesso à literatura como direito fundamental e as demandas da atualidade. 


\section{O Estado Democrático de Direitos enquanto garantidor dos Direitos Fundamentais}

A Constituição Federal Brasileira de 1988 adotou uma estrutura de Estado Social e Democrático de Direito em seu preâmbulo. Assim, está fundamentada na proteção dos direitos humanos e da dignidade da pessoa humana, considerando o ser humano com um valor supremo e desempenhando a função de garantidor de seus direitos.

Partindo desse pressuposto, doutrinadores juristas defendem a teoria do mínimo existencial (núcleo mínimo de direitos fundamentais) no âmbito da teoria da aplicabilidade dos direitos fundamentais como propósito de garantia e efetivação de direitos aos cidadãos.

Considerando que a positivação de direitos na Constituição consiste em uma convenção humana derivada do "contrato social", (posteriormente explanado) essa teoria não pode ser compreendida como mera utopia vaga ou ideal abstrato, prevalecendo a força normativa da Constituição, razão pela qual os direitos fundamentais são dotados de aplicabilidade, a fim de concretizar condições mínimas existenciais humanas ao povo brasileiro.

No Brasil, é perceptível a desigualdade social, definida por classes e criada devida à má distribuição da renda, resultando em estado de miserabilidade de alguns, enquanto outros se encontram em pleno estado de riqueza, o que é um fato decorrente do sistema capitalista, afirma Iamamoto \& Carvalho (2008, p.77).

Essa questão social fomenta a necessidade de se pensar/pesquisar soluções jurídicas que garantam a materialização e concretização de normas que asseguram condições mínimas de existência humana, asseguram Streck \& Morais (2010, p. 103-104). Tais soluções têm o desígnio de garantir a concretização da dignidade da pessoa humana, dos direitos humanos, e dos direitos fundamentais, como formas de erradicação da imensa desigualdade social que atinge os cidadãos, com violência à sua dignidade.

Sobre essa temática, Sarlet (2007, p. 25) afirma que "segue particularmente agudo o perene problema da eficácia e efetivação dos direitos fundamentais, de modo especial em face do ainda não superado fosso entre ricos e pobres". Apesar de haver a universalização e multiplicação dos direitos - com a positivação de extenso rol dos direitos humanos em tratados internacionais e a consagração de amplo catálogo dos direitos fundamentais na Constituição -, nota-se que ainda existe grande distanciamento entre a teoria e a prática. Isto se percebe a partir da análise da conjuntura social, concluindo-se que ainda existe violação dos direitos dos cidadãos, de diferentes formas, mesmo com a existência de diversas declarações de direitos. 
A caput do artigo $5^{\circ}$ da Constituição Federal de 1988 garante que "todos são iguais perante a lei, sem distinção de qualquer natureza [...]". A seguir, no artigo 227, o mesmo diploma legal determina que caberá ao Estado e à família o dever de assegurar à criança e ao adolescente, com “absoluta prioridade", o direito à educação, não cabendo qualquer forma de negligência desse direito.

Assim, o problema consiste não somente na necessidade de reconhecimento de mais direitos, ou apenas na existência de mais documentos que os expressem, mas a problemática que se estabelece, sobretudo, está no desafio da aplicação e implementação desses direitos. Os direitos já consagrados no texto da Constituição perdem sua eficácia quando não são aplicados de acordo com as necessidades efetivas da sociedade, deixando de promover a justiça social. Logo, o Estado deve gerar políticas públicas e, respectivamente, organismos que garantam a materialidade dos direitos, condizentes com o avanço, com as necessidades e com a realidade da atual sociedade, a fim de promover uma vida digna e com qualidade para todos.

Quanto à formação da sociedade e do Estado, numa abordagem da origem histórica da humanidade civilizada, na Teoria do Contrato Social, elaborada por autores chamados de contratualistas, como Jean Jacques Rousseau, Thomas Hobbes, John Locke, Charles-Louis de Secondat (Montesquieu), a formação da Sociedade ocorreu voluntariamente, e racionalmente, com a formulação de um "contrato hipotético", consistente no "acordo de vontades", devido aos interesses comuns dos seres humanos, concernentes na paz, proteção, segurança, e harmonia, que só encontrariam em união, na sociedade, é o que explica Dallari (2011, p. 23;24).

Com base nesta teoria, afirma-se que a formação do Estado ocorreu quando, de forma abstrata, artificial, e fictícia, a sociedade convencionou e delegou poderes e autoridade a uma entidade ou instituição, cuja criação e organização se originaram pela própria sociedade, e tiveram por finalidade a geração de sua representação, através de acordo de vontades, com a renúncia de direitos individuais, em troca da proteção e segurança coletivas, acrescenta Dallari (2011, p. 23). Isso significa que "o pacto social justifica todo o seu poder no mútuo consentimento de todos os seus integrantes", pois houve "a soma de pactos recíprocos e sucessivos", ensina Bastos (2004, p. 53).

Em outras palavras, conforme a Teoria do Contrato Social, tanto a Sociedade como o Estado se desenvolveram de forma consciente, com a escolha e o planejamento de sua construção e constituição, que se realizou com a negociação de decisões conjuntas das pessoas. Assim, houve a passagem do estado de natureza para o estado de civilização, em que o Estado, devido a esta transferência de poder e autoridade da sociedade a uma organização representativa 
concentrada, adquiriu deveres, obrigações, e responsabilidades em relação ao povo, lhe devendo garantias, segurança e proteção (DALLARI, 2011, p. 25).

O Estado surgiu como sociedade politicamente organizada com a concentração e com a centralização de poder, o que o torna soberano, correspondendo a ele a autoridade, desde que seja reflexo da vontade da população, adverte Bastos (2004, p. 42;43). Assim, o Estado, como organização ou instituição criada e convencionada pela vontade geral e representativa do povo, apenas possui legitimidade em relação ao que for da vontade da população. Portanto, a soberania é de titularidade do povo, mas por ele delegada ao Estado. Logo, o Estado, em essência, só existe por vontade e em função do povo que representa.

Bastos (2004, p. 56) instrui que foi desta maneira que se criaram os ordenamentos jurídicos a fim de se estabelecer a organização do Estado, a ordem da sociedade e os direitos e os deveres do governo e da população; inclusive no que se refere à forma de atuação do poder, que deveria considerar o consentimento de todos, pois é isso que fundamentaria a legitimidade das normas.

Dallari (2011, p. 150) afirma que a positivação de direitos na Constituição consiste em uma convenção humana derivada do "Contrato Social”, logo, a Constituição é o instrumento de garantia de que ninguém viole a dignidade humana, e que nem mesmo as instituições e os Estados se prevaleçam, pela utilização da força e da soberania para cometer atrocidades. $\mathrm{Ou}$ seja, é uma forma de limitação do arbítrio do poder governamental e da atuação pública, bem como um modo uniforme de assegurar que a própria sociedade, de forma geral, não desrespeite os direitos uns dos outros, sendo a Constituição o meio de delimitação de direitos de todos e determinação de deveres de cada um em relação aos outros, assegura Barroso (2011, p. 69). O mesmo autor ainda afirma que há previsibilidade, programação, e controle das atividades estatais, pois a atuação do Estado está condicionada à Constituição e, sendo esta alicerçada em um Estado Democrático de Direito, possui sua base na vontade do povo e as normas nela contidas possuem obrigatoriedade e vinculação, devendo ser obedecidas e respeitadas.

Com a evolução/mudança histórica da humanidade, se alastrou a preocupação mundial com a proteção da dignidade da pessoa humana, principalmente após as atrocidades e barbáries cometidas na Segunda Guerra Mundial, percebendo-se a necessidade de se oficializar, por meio de documentos, os direitos humanos no âmbito universal, assegura Fachin (2009, p. 57-61). Desse modo, em 1948, as Nações Unidas criaram a Declaração Universal dos Direitos Humanos, para que todas as Constituições internas de cada país reconhecessem, respeitassem e se fundamentassem na dignidade da pessoa humana, visto que a essência humana é única, acrescenta Fachin (2009, p. 63-77). 
Por isso, tem-se a dignidade da pessoa humana como fonte e postulado de todo sistema jurídico, uma vez que o ser humano deve ser o núcleo do Direito e, portanto, a dignidade da pessoa humana é o princípio matriz que deve ser inalterável em qualquer circunstância em que as pessoas estejam. $\mathrm{O}$ direito fundamental à educação (e esse viabilizado e ampliado por meio do ensino adequado da literatura) é também responsável pela promoção da dignidade humana do indivíduo, principalmente quando em formação.

Na mesma perspectiva, o Estatuto da Criança e do Adolescente, no artigo $3^{\circ}$, prevê que a criança e o adolescente desfrutam de "todos os direitos fundamentais inerentes à pessoa humana [...], assegurando-se-lhes todas as oportunidades e facilidades, a fim de lhes facultar o desenvolvimento físico, mental, moral, espiritual e social, em condições de liberdade e de dignidade". Considerando que a qualidade de humanidade é comum a todos, e considerando a dignidade da pessoa humana do indivíduo em formação, presume-se que há direitos fundamentais e essenciais que garantem a existência das pessoas e o desenvolvimento pleno da vida dos indivíduos, sendo

dever da família, da comunidade, da sociedade em geral e do poder público assegurar, com absoluta prioridade, a efetivação dos direitos referentes à vida, à saúde, à alimentação, à educação, ao esporte, ao lazer, à profissionalização, à cultura, à dignidade, ao respeito, à liberdade e à convivência familiar e comunitária. (ESTATUTO DA CRIANÇA E DO ADOLESCENTE, artigo $4^{\circ}$ )

Além de serem direitos prioritários na prestação às crianças e adolescentes, esses direitos são intrínsecos e inatos, portanto, indispensáveis, inalienáveis, irredutíveis, irrestringíveis, insuprimíveis, indisponíveis, irrenunciáveis, intransponíveis, imprescritíveis, e incondicionados, conforme ensina Sarlet (2005, p. 18-20), acrescentando que tratam-se de direitos naturais, decorrentes da qualidade de ser humano, por isso, são direitos gerais e comuns a toda humanidade, independentemente do lugar onde vivem e de suas características, pois são condições para suprir necessidades básicas.

Desta feita, embora as normas constitucionais demandem interpretação diante do contexto histórico e da conjuntura social, devem ser cumpridas devido à sua imperatividade e comando que vincula a todos, posto não serem apenas recomendações, mas possuírem força normativa decorrente da natureza da ciência jurídica, pois o Direito Constitucional possui a função de regulamentar, organizar, ordenar o Estado e a sociedade, e não apenas estudar os fenômenos e os fatos sociais e políticos, adverte Hesse (2009, p. 123-146).

Ademais, à criança e ao adolescente não cabe omissão, nem negligência aos seus direitos fundamentais, pois "nenhuma criança ou adolescente será objeto de qualquer forma de 
negligência, discriminação, exploração, violência, crueldade e opressão, punido na forma da lei qualquer atentado, por ação ou omissão, aos seus direitos fundamentais" (ESTATUTO DA CRIANÇA E DO ADOLESCENTE, artigo $5^{\circ}$ ).

Vislumbra-se, então, a necessidade de uma ação positiva do Estado, promovendo políticas públicas sociais/educacionais a fim de proporcionar o melhoramento na qualidade educacional, providenciando recursos aos Estados a fim destes cumprirem o disposto em suas legislações específicas - neste caso, a preparação de professores, o material didático específico e o consequente amadurecimento do aluno como leitor pela aplicação do Método Recepcional e outras formas de promover o desenvolvimento intelectual e cognitivo do aluno, conforme disposto nas Diretrizes Curriculares de Língua Portuguesa do Paraná.

O ser humano possui dignidade porque é considerado para além de sua matéria. Isto significa que ele possui necessidades físicas, psicológicas, mentais, sociais, etc. Assim, devem existir direitos que garantam um mínimo de condições existenciais humanas, para a proteção da dignidade da pessoa humana, considerando o ser em suas diversas dimensões. Em virtude da importância dos direitos fundamentais sociais para a vida das pessoas, o Estado não pode se eximir ou desobrigar a prestar o mínimo de condições existenciais humanas.

Neste caso, pode-se defender o direito à literatura como um direito fundamental implícito, decorrente do mínimo existencial, devendo ser efetivado para que se cumpra o disposto na Constituição Federal quanto ao direito fundamental à educação, uma vez que a educação é "direito de todos e dever do Estado e da família", devendo ser "promovida e incentivada com a colaboração da sociedade, visando ao pleno desenvolvimento da pessoa, seu preparo para o exercício da cidadania e sua qualificação para o trabalho" (CONSTITUIÇÃO FEDERAL, artigo 205).

\section{Abordagem Sociológica das Questões Educacionais na Contemporaneidade}

Buscando investigar temas relevantes à educação nas sociedades contemporâneas, a fim de estabelecer relações entre o acesso à literatura como direito fundamental e as demandas da atualidade, trataremos de estudos do sociólogo Zigmunt Bauman (2003). Numa abordagem sobre educação e juventude, o autor adverte que "a cultura é uma faca pressionada contra o futuro", além de ser uma revolução permanente, chamando a atenção do leitor sobre a negação de direitos políticos, econômicos e sociais a "uma parcela substantiva da população", fazendo minar os princípios democráticos. Reconhecendo as consequências em cercear os direitos mínimos necessários ao desenvolvimento do jovem, Bauman ensina que a memória do 
sofrimento próprio não tornará esse estudante numa pessoa generosa, gentil ou sensível à dor do outro, mas, ao contrário, estimulará os descendentes das vítimas a agirem cruelmente com os descendentes dos responsáveis pela crueldade, "e isso é usado como recibo de pagamento antecipado pela insensibilidade e como um cheque em branco pela desumanidade". Assim, a violência, a desumanidade e a humilhação desencadearão num nó resistente à ruptura, "por mais afiada que seja a espada que se empunhe” (BAUMAN, 2003, p. 14).

A prática de ensino não consiste em fazer os alunos "engolirem" um conjunto de regras e noções e depois expelirem-nas, sem provocar efeito algum na "digestão", ou seja, sem absorção cultural e valorativa. Partindo desse pressuposto, há uma abordagem de um provérbio chinês na mesma obra de Bauman (2003, p. 22) que afirma: "se queres colher em um ano, deves plantar cereais. Se queres colher em uma década, deves plantar árvores, mas se querer colher a vida inteira, deves educar e capacitar o ser humano". O autor ainda ensina que, "para ser prático, o ensino de qualidade precisa provocar e propagar a abertura, não a oclusão mental" (2003, p. 25).

Ao ser indagado se ainda podemos ter esperança e expectativa de que "nossos filhos e alunos se comportem diferentemente da maneira como a maioria hoje se comporta", frente aos "modismos e peculiaridades aparentemente irresistíveis que hoje prevalecem”, Bauman (2003, p. 28) responde afirmativamente, acrescentando de maneira otimista que "mesmo carvalhos centenários desenvolveram-se a partir de bolotas ridiculamente minúsculas".

O trabalho do professor, por vezes, é desconsiderado e "esse investimento de longo prazo nos filhos exigiria a participação ativa que os pais, ocupados demais e presos à armadilha consumista, não estão dispostos a pagar" (BAUMAN, 2003, p. 32).

Bauman (2003, p. 34) afirma que a geração atual de jovens é desconhecida das anteriores, pois trata-se de uma “sociedade de consumidores e uma cultura 'agorista' - inquieta e em perpétua mudança - que promove o culto da novidade e da contingência aleatória". A essa geração são ofertadas "quantidade crescente de informações" a "uma velocidade cada vez maior", tornando-se "progressivamente difícil criar narrativas, ordens e sequências de desenvolvimento", o que acarreta consequências às "maneiras como nos relacionamos com o conhecimento" (BAUMAN, 2003, p. 35;36).

A sabedoria a longo prazo, ocupada pela "arte de aprofundar-se", foi substituída pela “arte de surfar" e, "se o esquecimento rápido é consequência da aprendizagem rápida e superficial, longa vida à aprendizagem rápida (curta, temporária, rasteira)", adverte Bauman (2003, p. 37;38). 
Dessa forma, em oposição à cultura do mundo contemporâneo acelerado, cujo conhecimento não tem viés duradouro e permanente, pode-se propor o ensino da literatura na escola, estimulando-o desde as séries iniciais do ensino fundamental, a fim de proporcionar, ao indivíduo leitor, uma formação crítica e sólida, cooperando para a formação saudável de seu psiquismo (abordagem mais aprofundada a seguir, com os estudiosos da literatura).

Os jovens da atualidade não foram preparados para a chegada do "novo mundo inflexível, inóspito e pouco atraente", um mundo em que há "degradação dos valores e desvalorização dos méritos obtidos”, com as "portas fechadas e empregos escassos", um mundo de "expectativas transitórias e durabilidade de derrotas", cujos projetos são natimortos e as esperanças são frustradas (BAUMAN, 2003, p. 45).

Corroborando com essa coisificação da juventude, Bauman (2003, p. 56) afirma que é "estéril e perigoso acreditar que se pode dominar o mundo todo graças à internet quando não se tem uma cultura que possibilite descobrir e separar a boa da má informação", ou seja, a internet e os avanços tecnológicos por si só não são capazes de educar, mas servem de iscas para empobrecer os valores morais e éticos da juventude que, manipulada, não percebe que está sendo o produto da sociedade consumerista.

Considerando a eficácia da aplicação de métodos específicos que proporcionam o amadurecimento do aluno como leitor, as palavras de Bauman (2003, p. 104) vão ao encontro dessa perspectiva, quando afirma que a compulsão das crianças e jovens em se manterem conectados continuamente com seus pares do Facebook ou Twitter acaba por atrofiar a criatividade, acrescentando que "se você está sempre conectado, pode ser que nunca esteja verdadeira e completamente só" e, caso nunca esteja só, terá "menos chance de ler um livro por prazer, de desenhar um retrato, de contemplar uma paisagem pela janela e imaginar mundos diferentes do seu".

Caberá à literatura o papel do resgate do sistema cognitivo do aluno, tão atrofiado por informações desconectadas e viciadas, disponíveis nas redes sociais. Tais informações não incentivam o perfeito funcionamento do cérebro, que precisa da prática e do estímulo dos sentidos para consolidar o aprendizado. "Quanto maior o número de sentidos ou sensações for acionado no processo de aprendizado, mais caminhos o cérebro abrirá para fortalecer o conhecimento", reconhece Silva (2014, p. 112). Praticando a leitura de obras literárias, as “estradas de informações” serão acionadas no cérebro e mais facilmente o aluno será conduzido ao aprendizado, pois o cérebro é "como se fosse uma grande rodovia com um fluxo enorme de carros indo para lá e para cá sem sinais nem paradas" (SILVA, 2014, p. 113). Assim, "nosso conhecimento é uma rede de informações interligadas através de seus significados, percepções 
e sentimentos", logo, "nosso conhecimento é composto por uma rede multidimensional de informações interligadas", que precisam ser estimuladas pelo processo da leitura (SILVA, 2014, p. 114).

O estudo do desenvolvimento intelectual na sociedade contemporânea é pertinente e se justifica quando o alvo é promover métodos específicos para estimular o ensino/aprendizagem dessa geração, por meio do seu amadurecimento como leitor.

\section{Estudos que justificam a necessidade do ensino de Literatura}

Considerando a construção jurídica que assegura o cumprimento do direito à literatura como direito mínimo existencial garantidor da dignidade da pessoa humana e as necessidades da educação na contemporaneidade dentro da perspectiva sociológica, passa-se a estudar a abordagem dos estudiosos da literatura sobre a necessidade de se ensinar literatura nas escolas, bem como promovê-la por meio de diferentes metodologias.

A parte de literatura das Diretrizes Curriculares de Língua Portuguesa é baseada no Método Recepcional de Bordini \& Aguiar que, por sua vez, foi embaseado na teoria da Estética da Recepção, de Hans Robert Jauss:

\footnotetext{
Optou-se por esse encaminhamento devido ao papel que se atribuiu ao leitor, uma vez que esse é visto como um sujeito ativo no processo da leitura, tendo voz em seu contexto. Além disso, esse método proporciona momentos de debates, reflexões sobre a obra lida, possibilitando ao aluno a ampliação do seu horizonte de expectativa. (DIRETRIZES CURRICULARES DE LÍNGUA PORTUGUESA PARA OS ANOS FINAIS DO ENSINO FUNDAMENTAL E MÉDIO, 2008, p. 74)
}

Quanto aos textos que fundamentam a abordagem escolhida nesse documento referencial, serão a seguir expostos.

Candido (1972, p. 803-809) apresenta a literatura com "função humanizadora", uma vez que ela é apta a "confirmar a humanidade do homem". O autor afirma haver uma necessidade universal de ficção e de fantasia inerente à natureza humana, uma vez que o homem (independentemente de sua idade ou grau de instrução) busca satisfação das suas necessidades elementares.

A função da literatura é integradora e transformadora da realidade, pois tem seu cerne originário na realidade e pode operar de maneira inconsciente e subconsciente, observa Candido, explicando a função educacional da literatura: 
As camadas profundas da nossa personalidade podem sofrer um bombardeio poderoso das obras que lemos e que atuam de maneira que não podemos avaliar. Talvez os contos populares, as historietas ilustradas, os romances policiais ou de capa-e-espada, as fitas de cinema, atuem tanto quanto a escola e a família na formação de uma criança e de um adolescente. (CANDIDO, 1972, p. 805)

A função educativa da literatura sobrepõe o ponto de vista exclusivamente pedagógico, pois, se a literatura forma, ela não forma de acordo com a pedagogia oficial, afirma Candido, instruindo que a literatura "age com o impacto indiscriminado da própria vida e educa como ela, - com altos e baixos, luzes e sombras, fugindo da instrução moral e cívica" (CANDIDO, 1972, p. 804). Advertindo que a literatura ensina tanto quanto a vida, não podendo ter aspectos banidos por convenções (partes censuradas), o autor (1972, p. 805) pontua que há obras que agem como "excitante da imaginação erótica", gerando, ainda na atualidade, questões polêmicas entre pais e professores e paradoxos conflitantes entre ideias convencionais da "literatura que eleva e edifica" e a força poderosa da literatura que inicia o aluno na vida. Assim, não existe uma literatura que ensine sobre o lado bom, ético e moral da vida. A literatura desperta o obscuro que os educadores tentam esconder. Não há como se valer do caráter pedagógico para separar as emoções politicamente corretas a serem despertadas na vida da criança porque, como ensina Candido, a literatura "não corrompe e nem edifica; mas, trazendo livremente em si o que chamamos o bem e o que chamamos o mal, humaniza em sentido profundo, porque faz viver" (CANDIDO, 1072, p. 806).

Citando a classificação de bens compreensíveis e bens incompreensíveis do sociólogo francês Joseph Lebret, Candido (1995, p. 240) ressalta que há bens considerados incompreensíveis, tais como alimento, casa e roupa, enquanto outros como cosméticos e enfeites considerados compreensíveis. Entretanto, a fronteira entre ambos é complexa. Cada época e cultura cria os próprios critérios de distinção entre os bens. É preciso haver um despertamento individual em cada cidadão de que as minorias precisam ter acesso aos bens materiais e à igualdade de tratamento, pontua o autor, acrescentando que, mais do que assegurar a sobrevivência física, os bens incompreensíveis deveriam garantir a integridade espiritual do cidadão.

São incompreensíveis certamente a alimentação, a moradia, o vestuário, a instrução, a saúde, a liberdade individual, o amparo da justiça pública, a resistência à opressão, etc.; e também o direito à crença, à opinião, ao lazer e, por que não, à arte e à literatura. (1995, p. 241)

Porém, a arte e a literatura só poderão ser consideradas bens compreensíveis numa organização justa da sociedade quando "corresponderem a necessidades profundas do ser 
humano, a necessidades que não podem deixar de ser satisfeitas sob pena de desorganização pessoal, ou pelo menos de frustração mutiladora" (CANDIDO, 1995, p. 256). A literatura é uma "manifestação universal de todos os homens em todos os tempos", observa o autor, pois não existe alguém sem a possibilidade de "entrar em contato com alguma espécie de fabulação" e "ninguém é capaz de passar as vinte e quatro horas do dia" sem sonhar, mergulhando no universo da ficção (CANDIDO, 1995, p. 242). Candido, então, aponta esta necessidade como universal, "que precisa ser satisfeita e cuja satisfação constitui um direito" e conclui:

Assim, como não é possível haver equilíbrio psíquico sem o sonho durante o sono, talvez não haja equilíbrio social sem a literatura. Deste modo, ela é um fator indispensável de humanização e, sendo assim, confirma o homem na sua humanidade, inclusive porque atua em grande parte no subconsciente e no inconsciente. (CANDIDO, 1995, p. 243)

Destarte, a literatura entra na educação como um instrumento intelectual e afetivo poderoso, formando personalidade "segundo a força indiscriminada e poderosa da própria realidade", entende Candido (1995, p. 243), considerando que "a produção literária tira as palavras do nada e as dispõe como um todo articulado", sendo este o primeiro nível humanizador, porque "a organização da palavra comunica-se ao nosso espírito e o leva, primeiro, a se organizar, em seguida, a organizar o mundo". Logo, requer-se uma coerência mental que ordenará o caos interior do leitor, permitindo que "os sentimentos passem do estado de mera emoção para o da forma construída" (CANDIDO, 1995, p. 246). A literatura também humaniza porque permite desenvolver no leitor a "quota de humanidade", tornando-o mais compreensivo e aberto à natureza, sociedade e ao seu semelhante: "a literatura corresponde a uma necessidade universal que deve ser satisfeita sob pena de mutilar a personalidade, porque pelo fato de dar forma aos sentimentos e à visão do mundo, ela nos organiza, nos liberta do caos" (CANDIDO, 1995, p. 256). Além disso, a literatura pode funcionar como um "instrumento consciente de desmascaramento", quando aborda "situações de restrição dos direitos, ou de negação deles, como a miséria, a servidão, a mutilação espiritual”, ligando-se diretamente com a luta pelos direitos humanos (CANDIDO, 1995, p. 256).

No entanto, para que a literatura erudita chegue às camadas menos privilegiadas, a organização da sociedade tem que se dar de forma justa, garantindo-se a distribuição equitativa dos bens, ensina Candido (1995, p. 257), lamentando que "numa sociedade estratificada (como no Brasil), a fruição da literatura se estratifica de maneira abrupta e alienante”. Desta forma, a luta pelos direitos humanos abarca a luta pelo acesso à cultura em suas diferentes formas por toda a sociedade. 
Considerando que a literatura deveria ser bem essencial e fundamental, constituindose um direito de todos, passamos a estudar os teóricos da Estética da Recepção e do Método Recepcional, que permitem viabilizar a efetivação do direito fundamental à educação.

\section{Método Recepcional e outras metodologias}

Zappone (2005, p. 253) indaga sobre quais seriam os processos que desencadeamos ao lermos, considerando-se a leitura enquanto "processo, habilidade e atividade social ou coletiva". A autora observa que a partir da década de 60 se preocupou de forma mais sistemática a estudar a literatura enquanto leitura, "a partir do redimensionamento das noções de autor, de texto e de leitor", acrescentando que, atualmente, o autor não detém mais o "sentido que sua produção pode suscitar", porque o texto não é considerado mais uma chave para a interpretação de determinada obra, uma vez que ele não mais "transmite pensamentos, informações ou ideias de seu produtor" e nem a linguagem é mais apta a "traduzir todas as intenções do falante". Após tais estudos, o texto passou a ser entendido como uma "estrutura cheia de lacunas e de nãoditos". Para a Estética da Recepção, o foco está no leitor, que passou a ser a "peça fundamental no processo de leitura", sendo responsável pela atribuição de sentido ao que lê, observa Zappone (2005, p. 253), acrescentando que as experiências de vida, as leituras anteriores e o momento histórico em que o texto é lido são elementos que influenciam o leitor no "processo de significação desencadeado na leitura de textos”.

Jauss (1994, p. 22) defende que a qualidade e a categoria estética de uma obra são auferidas pela soma dos efeitos produzidos quando a obra é recebida pelo público e comparada com obras anteriores, sendo sua fama posterior promovida a partir dos primeiros leitores. Tal obra não se prenderá apenas a eventos históricos passados, nem tampouco à representação das estruturas sociais e das lutas de classes, assegura o estudioso.

Quanto ao Marxismo, Jauss (1994, p. 24) acreditava que este reduzia a literatura a simples reflexo de estruturas sociais. Sua crítica estendia-se também ao Formalismo, que desconsiderava as condições históricas e entendia a literatura como uma estrutura autônoma, mas voltava à historicidade para buscar o seu caminho, pois a interpretação precisa considerar formas já existentes e o leitor não está dissociado deste processo de análise formal, pois é ele quem desvela a forma e atribui o sentido, não sendo a obra estanque, dotada de apenas um sentido.

Para resolver tais ausências, Jauss (1994, p. 28) propôs sete teses para uma nova história da literatura: $1^{\mathrm{a}}$ ) a historicidade da literatura não repousa numa conexão de fatos 
literários estabelecidos post factum, mas no experienciar dinâmico da obra literária por parte de seus leitores; $2^{\mathrm{a}}$ ) a experiência literária do leitor pressupõe um "saber prévio" que funciona como conjunto de saberes tanto literário quanto da própria vida, "com base no qual o novo de que tomamos conhecimento faz-se experienciável, ou seja, legível”; $3^{\text {a }}$ ) o caráter artístico de um texto pode ser medido: a noção de distância estética - afastamento ou não coincidência entre o horizonte de expectativa preexistente do público e o horizonte de experiência suscitado por uma nova obra; $4^{\mathrm{a}}$ ) o processo de interpretação é bem mais complexo e deve efetuar uma reconstrução do horizonte de expectativas a partir do qual uma obra foi criada e recebida; $5^{\mathrm{a}}$ ) caráter diacrônico do projeto de história literária. O lugar de uma obra literária não pode ser determinado apenas em razão de sua recepção inicial, portanto baseando-se apenas no contraste entre o novo e o velho no momento de sua aparição; $6^{\mathrm{a}}$ ) caráter sincrônico do projeto de história literária. As obras devem ser lidas a partir de sua história de recepções, num movimento diacrônico que articula várias fases, mas deve, também, articular a leitura da obra no momento de seu aparecimento; $7^{\text {a }}$ ) relação entre literatura e vida prática. A literatura é pensada não apenas em termos de seus efeitos estéticos, mas também a partir dos efeitos éticos, sociais, psicológicos que possa suscitar.

Baseando-se na teoria de Jauss, Bordini \& Aguiar (1993, p. 83) desenvolveram o Método Recepcional que se fundamenta no entendimento de que "a obra é um cruzamento de apreensões que se fizeram e se fazem dela nos vários contextos históricos em que ela ocorreu e no que agora é estudada".

As autoras explicam que há uma norma estética vigente para o leitor e, a partir desta norma, o texto vai se modificando continuamente. Entre o texto e o leitor há "horizontes históricos muitas vezes distintos e defasados", precisando fundir-se para que se efetive a comunicação, conhecido por "horizontes de expectativas" na teoria de Hans Robert Hauss (BORDINI \& AGUIAR, 1983, p. 83). Dentro do texto, "as expectativas do autor se traduzem e as do leitor são a ele transferidas", logo, tais horizontes podem "identificar-se ou estranharse", pontuam as autoras, acrescentando que esta expectativa serve como "parâmetro para a avaliação estética da literatura". A obra será valorizada quando for apta a "produzir alteração ou expansão do horizonte de expectativas do leitor", porque se oporá às "convenções conhecidas e aceitas" por ele, e também será perene quando "continuar contribuindo para o alargamento de horizontes de expectativas de sucessivas épocas" (BORDINI \& AGUIAR, 1983, p. 84).

A obra precisa ultrapassar o sistema de valores e normas do leitor a fim de operar desconforto na posição psicológica do leitor, ampliando seu horizonte de expectativa, contudo, 
ela não pode funcionar como algo que repele o leitor por seu grau de compreensão muito complexo, pois exigirá "um esforço de interação demasiado conflitivo com seu sistema de referências vitais", asseguram Bordini \& Aguiar (1983, p. 84). A modificação do horizonte de expectativas se dará mais facilmente conforme o número de leituras feitas. A obra difícil portará "o poder de transformação de esquemas ideológicos passíveis de crítica", assim, devendo ser priorizada nos pressupostos teóricos da estética da recepção. Logo, o professor partirá do horizonte de expectativa do aluno, propiciando condições de questionamento deste horizonte para, ao final, o aluno ser apto a "comparar e contrastar as atividades realizadas, questionando sua atuação" e fazendo uma "leitura mais exigente que a inicial em termos estéticos e ideológicos", concluem as autoras (1983, p. 85).

Cientes da necessidade de se estabelecer parâmetros quanto aos processos do ensino de literatura, Bordini \& Aguiar (1983, p. 86-91), inspiradas na teoria de Jauss, desenvolveram as seguintes etapas para o Método Recepcional: determinação do horizonte de expectativa: etapa em que se identificam os gostos, preferências, crenças, modismos, vivências dos alunos, preconceitos moral e social e interesses específicos da área de leitura, a fim de se traçar "estratégias de ruptura e transformação" deste horizonte de expectativa; atendimento do horizonte de expectativa: esta etapa consiste em satisfazer os gostos e preferências dos alunos, atendendo ao objeto que corresponda ao esperado e à estratégia de ensino organizada a partir de procedimentos conhecidos dos estudantes; ruptura do horizonte de expectativa: nesta fase se abalará as certezas e convicções dos alunos em termos de literatura ou vivência cultural, por meio de textos que se assemelhem aos anteriormente trabalhados em algum aspecto, contudo, com grau de dificuldade mais elevado. $\mathrm{O}$ aluno entrará num campo desconhecido, mas não absurdamente difícil, pois precisa se sentir seguro e não resistente à nova experiência; questionamento do horizonte de expectativa: esta fase consistirá na comparação entre as fases anteriores. Faz-se uma análise comparativa entre as experiências de leituras efetuadas até o momento, a classe avaliará seu comportamento em relação às leituras e aos desafios enfrentados, é um autoexame definindo superação e aspectos em que ainda remanescem as dificuldades, bem como caminhos para enfrentá-las; ampliação do horizonte de expectativa: nesta fase os alunos tomarão consciência das alterações e aquisições que as leituras dentro do Método Recepcional lhes proporcionaram.

O final da última etapa dará início à nova etapa de aplicação do método, que evoluirá em espiral, viabilizando um processo gradativo de crescimento intelectual e cultural, a fim de formar um leitor consciente e crítico. A literatura exercerá a função de fazer com que o sujeito 
compreenda melhor seu presente e seu papel como sujeito histórico, com influência nas estruturas sociais.

Dentre outras metodologias para o ensino de literatura, Cosson (2006) propôs o ensino de literatura por meio da Sequência Básica, com as seguintes etapas: motivação (visando preparar o aluno para a leitura do texto), com a observação do tema a ser trabalhado, além da observação da estrutura do texto e de sua temática; introdução (apresentação do autor e da obra), momento em que se abordam as informações básicas do autor e da obra a fim de despertar a curiosidade do leitor; leitura, momento em que se auxilia o aluno com o acompanhamento da efetiva leitura, com aplicação de intervalos a fim de auferir os resultados e perceber as dificuldades dos alunos; interpretação, fase em que se efetiva a construção de sentidos, com o compartilhamento e o registro das interpretações.

Cosson (2014) ainda propôs a Sequência Expandida para auxílio no ensino de literatura, com as seguintes etapas: motivação, a fim de antecipar o que será lido, preparando o aluno para o universo do livro; introdução, momento em que se localiza o autor e a obra no campo literário e histórico; leitura, realizada fora do ambiente escolar quando se tratar de narrativas longas; primeira interpretação, para auferir as impressões da leitura; contextualização, fase em que o professor trará informações sobre a obra em vários níveis como história, estilo, crítica, etc.; segunda interpretação, momento em que se somam os saberes advindos da primeira interpretação da obra e da contextualização; expansão, etapa em que se trabalhará a intertextualidade, dialogando com outras obras.

\section{Sugestão de sequência didática a partir de obras que abordam a temática tecnologia, trabalho e construção de identidades}

A sequência didática sugerida nesse artigo tem como tema "A Representação do Trabalho, da Opressão e da Fantasia na formação da criança" e sugere-se sua aplicação no $9^{\circ}$ ano do Ensino Fundamental, com atividades distribuídas em doze aulas. O objetivo central é a leitura da obra A Casa da Madrinha, da autora Lygia Bojunga.

Aplicando-se as etapas do Método Recepcional de Bordini \& Aguiar (1993), na determinação do horizonte de expectativas, o professor deverá trabalhar com a exploração infantil em publicidade, com imagens de crianças sensualizadas de capas da revista Vogue kids, disponíveis na internet. Além disso, o professor mostrará cenas de novelas em que crianças (atores) interpretam outras crianças que são exploradas por meio do trabalho (recurso multimídia). O intuito é mostrar a publicidade infantil em telenovelas, anúncios publicitários, 
filmes e outros meios midiáticos, a fim de delimitar o horizonte de expectativas do aluno. A partir da temática da exploração do trabalho infantil, o professor pedirá para os estudantes pensarem em um brinquedo ou amigo imaginário que os ajudem a suportar a realidade, caso eles vivenciassem a mesma situação (descrição ou desenho). A socialização voluntária de alguns alunos pode ser solicitada.

$\mathrm{Na}$ fase de atendimento do horizonte de expectativas, o professor buscará histórias em quadrinho cuja temática fuja da realidade dura por meio da fantasia, materializada num instrumento. (Exemplo: boneco Sansão como instrumento que torna a Mônica mais forte). Ainda nessa fase, o professor passará o trailer do filme As Crônicas de Nárnia - O leão, a feiticeira e o guarda-roupa, enfatizando a fuga da realidade por meio de objeto mágico "armário encantado escondido por um lençol que transporta a outro mundo", relacionando o conteúdo do trailer com a obra A Casa da Madrinha, no sentido de como Alexandre usava o sonho da casa fantástica da madrinha para suportar a dura realidade. Como sugestão para reflexão, o professor poderá propor as seguintes questões: O que é reino de Nárnia? Qual o instrumento usado para transportar os personagens da realidade à fantasia? Se pudéssemos criar um reino como Nárnia, como ele seria? Por quê? Tem algum lugar que você conhece ou gostaria de conhecer parecido com Nárnia? (Talvez algum dos alunos cite os parques da Walt Disney).

$\mathrm{Na}$ fase de ruptura do horizonte de expectativas, se fará a leitura em sala do conto $A$ pequena vendedora de fósforo (Hans Christian Andersen) e A Negrinha (Monteiro Lobato). Aqui, o professor poderá trabalhar com questões sobre o sofrimento de ambos os personagens.

$\mathrm{Na}$ fase de questionamento do horizonte de expectativas, o professor relacionará os dois contos (organizar a turma em grupos e solicitar uma representação gráfica que aborde um tema em comum em ambos os contos). A seguir, o professor solicitará aos alunos que comparem a obra de Andersen com a obra de Lobato, criando um outro final, mudando a realidade dos contos, utilizando instrumentos fantásticos.

A fase de ampliação do horizonte de expectativas (atrelada com a Sequência Básica de Rildo Cosson) comportará diferentes etapas. A Motivação (incitação da leitura proposta, se dá de forma lúdica, com uma temática relacionada ao texto literário que será lido) foi um momento já trabalhado em consonância com o Método Recepcional, na etapa “Atendimento do Horizonte de Expectativa". Na Introdução, o professor fará a apresentação do autor e da obra (A Casa da Madrinha), além de uma explanação breve sobre o conteúdo do livro. Na etapa Leitura, o professor fará a leitura coletiva dos três primeiros capítulos da obra A Casa da Madrinha, de Lygia Bojunga, em sala, com possibilidade de "intervalos" para aferição da leitura e saneamento de dúvidas de compreensão de vocabulário e interpretação, a fim de 
instigar o interesse ao longo da leitura. Na Interpretação, depois da leitura integral da obra, terminada em casa, a professora preparará dois momentos no intuito de fechar este ciclo, a saber: [A] Encontro do leitor com a obra: Um debate informal para verificar as impressões gerais dos alunos sobre o livro. Nessa etapa, o objetivo é que os alunos já estejam aptos para perceber o valor que o trabalho adquire no decorrer da obra e a função dos elementos mágicos na vida dos indivíduos (Exploração do papel do pavão na narrativa - penas, filtro que atrasa o pensamento, imitação -, casa da madrinha - para onde fugimos quando estamos com problemas emocionais ou financeiros?). [B] Materialização da interpretação: Com base nas discussões, a professora solicitará uma produção textual (sugestão: carta do leitor) em que deverão ser focalizados o valor do trabalho na sociedade e a interferência da fantasia na realidade. $\mathrm{Na}$ gênero sugerido, o aluno escreverá à determinada revista literária que supostamente acabou de lançar o livro A Casa da Madrinha, escrevendo sua opinião sobre o livro, com enfoque no trabalho e na fantasia como fuga deste, posicionando-se criticamente e considerando os seguintes elementos do gênero Carta do Leitor: data; nome da revista; vocativo (a quem se dirige); corpo do texto (com linguagem apropriada); despedida cordial; assinatura. A professora mostrará um modelo, trabalhando com exemplos antes da produção.

Expandido o conhecimento: (Sequência Expandida - Rildo Cosson). A partir do texto trabalhado dentro do seu contexto histórico, a professora abordará o processo de intertextualidade, explorando os diálogos possíveis com outras obras em três etapas: [A] O evento histórico da Ditadura Militar no Brasil será explorado em vídeos curtos, imagens de pessoas que sofreram as consequências da repressão e matérias jornalísticas referentes à Ditadura (disponível na internet); [B] Imagens e vídeos das manifestações de 15 de março de 2015 contra o atual governo do país, abordando os pedidos da população por intervenção militar. O professor levantará a questão sobre a manifestação ser uma ação consciente ou inconsciente da população quanto às consequências da volta à Ditadura Militar (mostrar imagens das solicitações da manifestação); [C] Leitura e análise do preâmbulo da Constituição Federal do Brasil (1988). A professora explicará o valor de uma Constituição como um documento que significa a ruptura com o ordenamento constitucional anterior e a construção de um novo Estado, sendo o Preâmbulo um instrumento que veicula a promulgação, a origem, as justificativas, os objetivos, os valores e os ideais de uma Constituição, servindo de vetor interpretativo para a compreensão do significado das suas prescrições normativas e solução dos problemas de natureza constitucional (disponível online); [D] Reescrita da Carta do Leitor, agora para outro veículo de comunicação, qual seja, uma revista atual que propõe uma matéria sobre as manifestações. Importante que o aluno relacione o conteúdo do livro (A Casa da 
Madrinha) produzido durante o período da Ditadura Militar no Brasil e as manifestações atuais pedindo a volta da intervenção militar, bem como o valor da Democracia instituído no Preâmbulo da Constituição Federal do Brasil. Esse gênero é apropriado para trabalhar o valor da manifestação de opinião durante a vigência de um Estado Democrático de Direitos e sua supressão durante a Ditadura Militar.

\section{Considerações finais}

O desenvolvimento da pesquisa proporcionou a compreensão dos direitos fundamentais inerentes à pessoa humana a fim de promover-lhe a sua dignidade, pois ela é o centro do ordenamento jurídico. Tais direitos precisam ser proporcionados à criança e ao adolescente pelo Estado e pela família, além de serem incentivados pela sociedade. O contido nos diplomas legais não deve ser interpretado como mero ideal abstrato, mas precisa ser cumprido, uma vez que o Estado existe em função da garantia dos interesses do povo. A viabilização do direito pleno à educação se dará a partir do estímulo do ensino à literatura no ambiente escolar, uma vez que ela é apta a humanizar o indivíduo, equilibrar-lhe seu sistema psíquico, lhe proporcionando ferramentas de ampliação de seu sistema cognitivo e lhe dando empoderamento para transitar em discursos alheios ao seu convívio, pois permite o desenvolvimento do raciocínio crítico.

Para a aplicação do ensino da literatura, foram necessários os conceitos sociológicos da educação na contemporaneidade, a fim de estabelecer relações entre o acesso à literatura como direito fundamental e as demandas da atualidade. É preciso compreender para quem se ensina e quais os instrumentos pertinentes para o sucesso dessa atividade, pois o que se defende é o papel da literatura para o resgate do sistema cognitivo do aluno, tão atrofiado por informações desconectadas e viciadas, disponíveis nas redes sociais.

Metodologias específicas foram desenvolvidas para se buscar esse fim pretendido e, a partir desse levantamento teórico, desenvolveu-se uma sequência didática como sugestão para o aperfeiçoamento da prática pedagógica no ensino da literatura a fim de se efetivar, com êxito, o direito fundamental à educação do aluno, em respeito à sua dignidade humana. 


\section{Referências}

AGUIAR, Vera Teixeira de; BORDINI, Maria da Glória. Literatura e Formação do leitor: alternativas metodológicas. Porto Alegre: Mercado Aberto, 1993.

BARROSO, Luís Roberto. Curso de Direito Constitucional Contemporâneo: Os conceitos fundamentais e a construção do novo tempo. 3. ed. São Paulo: Saraiva, 2011.

BASTOS, Celso Ribeiro. Curso de Teoria Geral do Estado e Ciência Política. 6. ed. São Paulo: Celso Bastos Editora, 2004. p. 53.

BAUMAN, Zygmunt. SOBRE EDUCAÇÃO E JUVENTUDE. Rio de Janeiro: Zahar, 2013.

BRASIL. Constituição da República Federativa do Brasil de 1988. Disponível em: $<$ http://www.planalto.gov.br/ccivil_03/Constituicao/Constituicao.htm>. Acesso em: 17 nov. 2014.

BRASIL. Estatuto da Criança e do Adolescente. Disponível em: $<$ http://www.planalto.gov.br/ccivil_03/leis/18069.htm>. Acesso em: 17 nov. 2014.

CANDIDO, Antonio. A literatura e a formação do homem. in: Ciência e Cultura. São Paulo, Vol. 4, n. 9, PP 803-809, set/1972.

. O direito à literatura. in: Vários Escritos. 3. ed. rev, e ampl. São Paulo: Duas Cidades, 1995. pp. 235 - 263.

DALLARI, Dalmo de Abreu. Elementos de Teoria Geral do Estado. 30. ed. São Paulo: Saraiva, 2011.

FACHIN, Melina Girardi. Fundamentos dos Direitos Humanos - Teoria e práxis na cultura da tolerância. Rio de Janeiro: Renovar, 2009. p. 57-61.

HESSE, Konrad. Temas Fundamentais do Direito Constitucional. São Paulo: Saraiva, 2009.

IAMAMOTO, Marilda Vilela; CARVALHO, Raul de. Relações Sociais e Serviço Social no Brasil: Esboço de uma interpretação histórico metodológica. 24. ed. São Paulo: Cortez, 2008.

JAUSS, Hans Robert. A Literatura como Provocação - História da Literatura como Provocação Literária. São Paulo: Editora Ática, 1994.

PARANÁ, Secretaria de Estado da Educação. Diretrizes Curriculares de Língua Portuguesa para os Anos Finais do Ensino Fundamental e Ensino Médio. Curitiba, 2008.

SARLET, Ingo Wolfgang. A eficácia dos Direitos Fundamentais. 8. ed. Porto Alegre: Livraria do Advogado, 2007.

. Os Direitos Fundamentais Sociais na Constituição de 1988. Disponível em: <http://www.direitopublico.com.br/pdf_seguro/REVISTA-DIALOGOJURIDICO-01-2001-INGO-SARLET.pdf>. Acesso em: 23 abr 2013. 
(org.). As Dimensões da Dignidade da Pessoa: Construindo uma compreensão jurídico-constitucional necessária e possível. In: MAURER, Bèatrice et. al. Dimensões da Dignidade: Ensaios de Filosofia do Direito e o Direito Constitucional. Porto Alegre: Livraria do Advogado, 2005.

SILVA, Ana Beatriz Barbosa. Mentes Consumistas: do consumo à compulsão por compras. $1^{a}$ Ed. São Paulo: Globo, 2014.

STRECK, Lenio Luiz; MORAIS, José Luiz Bolzan de. Ciência Política e Teoria do Estado. 7. ed. Porto Alegre: Livraria do Advogado, 2010.

ZAPPONE, Miriam Hisae Yaegashi. Estética da Recepção. in: BONNICI, Thomas; ZOLIN, Lucia Osana (Orgs.) Teoria Literária: abordagens históricas e tendências contemporâneas. 2. ed. rev. e ampl. Maringá: Eduem, 2005. 